\title{
Occurrence and fate of steroid estrogens in the largest wastewater treatment plant in Beijing, China
}

\author{
Yiqi Zhou • Jinmiao Zha $\cdot$ Zijian Wang
}

Received: 14 May 2011 / Accepted: 15 November 2011 /Published online: 3 December 2011

(C) Springer Science+Business Media B.V. 2011

\begin{abstract}
Concern over steroid estrogens has increased rapidly in recent years due to their adverse health effects. Effluent discharge from wastewater treatment plants (WWTPs) is the main pollutant source for environmental water. To understand the pollutant level and fate of steroid estrogens in WWTPs, the occurrence of estrone (E1), 17- $\beta$-estradiol (E2), estriol (E3), and 17- $\beta$ ethinylestradiol (EE2) was investigated in the Gaobeidian WWTP in Beijing, China. Water samples from influent as well as effluent from second sedimentation tanks and advanced treatment processes were taken monthly during 2006 to 2007. In influent, steroid estrogen concentrations varied from 11.6 to $1.1 \times$ $10^{2} \mathrm{ng} / \mathrm{l}, 3.7$ to $1.4 \times 10^{2} \mathrm{ng} / \mathrm{l}$, no detection (nd) to $7.6 \times 10^{2} \mathrm{ng} / 1$ and nd to $3.3 \times 10^{2} \mathrm{ng} / \mathrm{l}$ for E1, E2, E3, and EE2, respectively. Compared with documented values, the higher steroid estrogen concentrations in the WWTP influent may be due to higher population density, higher birthrate, less dilution, and different sampling time. Results revealed that a municipal WWTP with an activated sludge system incorporating anaerobic, anoxic, and aerobic processes could eliminate natural and synthetic estrogens effectively. The mean elimination efficiencies were $83.2 \%, 96.4 \%$, $98.8 \%$, and $93.0 \%$ for E1, E2, E3, and EE2,
\end{abstract}

Y. Zhou $\cdot$ J. Zha $\cdot$ Z. Wang $(\bowtie)$

State Key Laboratory of Environmental Aquatic Chemistry, Research Center for Eco-Environmental Sciences,

Chinese Academy of Sciences,

PO Box 2871, Beijing 100085, People's Republic China

e-mail: wangzj@rcees.ac.cn respectively. The major removal mechanism for natural estrogens and synthetic estrogen EE2 were biodegradation and sorption on the basis of mass balance in water, suspension particles, and sludge. In the WWTP effluent, however, the highest concentrations of E1, E2, E3, and EE2 attained were 74.2, $3.9,5.1$, and $4.6 \mathrm{ng} / \mathrm{l}$, respectively. This is concerning as residual steroid estrogens in WWTP effluent could lead to pollution of the receiving water. Advanced flocculation treatment was applied in the WWTP and transformed the residual estrogen conjugates to free species, which were reduced further by filtration with removal shifting from $32 \%$ to $57 \%$ for natural estrogen, although no EE2 was removed.

Keywords EDCs · Steroid estrogen - Wastewater · Presence $\cdot$ Removal

\section{Introduction}

Endocrine disrupters are exogenous agents that interfere with the synthesis, secretion, transport, binding, action, and elimination of natural hormones responsible for the maintenance of homeostasis, reproduction, development, and behavior (US Environmental Protection Agency 1997). Chemicals such as xeno-estrogens alkylphenols, bisphenol A, phthalate, pesticides, polyaromatic compounds, and steroid estrogen are considered to be endocrine disrupters (Desbrow et al. 1998; Jobling et al. 1998). Natural 
estrone (E1), 17- $\beta$-estradiol (E2), estriol (E3), and synthetic $17-\beta$-ethinylestradiol (EE2) are of concern due to their higher estrogenic activity and ubiquitous nature. Previous study showed that they are effective to induce biological effects even at lower concentrations (Routledge et al. 1998; Rodgers-Gray et al. 2000; Zha et al. 2008), and they have been found in sludge treatment plant effluent, river water, surface water, and drinking water (Desbrow et al. 1998; Larsson et al. 1999; Baronti et al. 2000; Johnson et al. 2000; Rodgers-Gray et al. 2000; Servos et al. 2005; Vethaak et al. 2005).

Natural estrogens E1, E2, and E3 are primarily excreted by humans and animals at conjugated estrogen without estrogenic activity and then degraded to active forms (D'Ascenzo et al. 2003). A previous study of a typical cross-section of 73 Italian women determined that average excretion of conjugated E1, E2, and E3 was 32, 14, and $106 \mu \mathrm{g} /$ day, respectively. These excretions were discharged into the aquatic environment through WWTP effluent. Municipal wastewater treatment plants are major sources of natural estrogens due to their incomplete removal as activated sludge treatment is primarily designed to remove nutrient enrichment and microbial contamination. Consequently, WWTP effluent is a major route for the release of natural estrogens into receiving water bodies (Desbrow et al. 1998; Johnson and Sumpter 2001; Kolpin et al. 2002).

Synthetic estrogen EE2 is a major ingredient in the contraceptive pill, amounting to an intake of approximately $35 \mu \mathrm{g} /$ day. In addition to contraception, EE2 is also widely used in the management of menopausal and postmenopausal syndrome, physiological replacement therapy in deficiency states, and the treatment of prostatic and breast cancer in postmenopausal women (Peter 1990; Tyler et al. 1998; Birkett and Lester 2003; Atalay et al. 2005). This synthetic hormone is of particular concern due to its high persistence in the environment and estrogenic activity. Concentration levels of natural and synthetic estrogens in WWTP influent and effluent has been well documented (Desbrow et al. 1998; Andersen et al. 2003; Braga et al. 2005), but the removal efficiency of natural and synthetic steroid estrogens in WWTPs can be influenced by rainfall (Shore et al. 1993; Kirk et al. 2002), temperature (Tabak et al. 1981; Desbrow et al. 1998; Ternes 1998; Belfroid et al. 1999; Baronti et al. 2000), and hydraulic and sludge retention times (Ternes et al. 1999a; Johnson et al. 2000; Kirk et al. 2002; Andersen et al. 2003; Svenson et al. 2003; Cargouët et al. 2004). Previous research developed a model to estimate influent and effluent concentrations of steroid estrogens at sewage treatment plants (Johnson and Williams 2004); however, due to a lack of correlative information including water flow, population, WWTP operation parameters, and analysis methodology differences, and difficulty in determining steroid estrogens in complex matrices, estimated results have not always agreed with the monitored data. Consequently, monitoring influent and effluent steroid estrogen concentrations and assessing their fate in different areas and different WWTP treatment processes are essential. Previous reports have shown estrogenic activity in effluent from large sewage treatment plants in Beijing (Ma et al. 2005, 2007) and revealed the presence of steroid estrogens in WWTP influent and effluent in China (Jin et al. 2008; Chang et al. 2011; Zhou et al. 2011). However, studies on seasonal variation and the removal and degradation mechanism of steroid estrogens in WWTPs are absent in China. In the present study, we focused on the occurrence and fate of steroid estrogens in the largest WWTP in Beijing, China, to provide first-hand data for the control and management of estrogen pollutants.

\section{Materials and methods}

WWTP selection and sample collection

The selected WWTP (Gaobeidian Wastewater Treatment Plant) is the largest in China (Ma et al. 2005) and is located in the Chaoyang District of Beijing. It treats a mean flow of $1,000,000 \mathrm{~m}^{3} /$ day and services a population of approximately $2,400,000$ people. A second activated sludge treatment was applied to eliminate nitrogen and phosphorus. This treatment process includes an aerated grit chamber, a primary sedimentation tank, an $\mathrm{A}^{2} \mathrm{O}$ (anaerobic, anoxic, and aerobic) tank, and a secondary sedimentation tank. The hydraulic retention time is $4-12 \mathrm{~h}$, the sludge retention time is $5-15$ days, and sludge concentration is 1,000-1,400 mg/l (Sun et al. 2007). The WWTP receives domestic and industrial wastewater in equal measures. Part of the effluent from the secondary sedimentation tank is treated with flocculation and filtration for reuse, with the surplus water discharged 
into Gaobeidian Lake and Tonghui River. A detailed plot of the WWTP and sampling points is shown in Fig. 1.

Grab water samples were collected using glass bottles previously detergent washed, acid rinsed, and dried at $120^{\circ} \mathrm{C}$ for $6 \mathrm{~h}$, with $5 \%$ o $(v / v)$ methanol added immediately after collection to prevent growth of microorganisms. Samples were stored at $4{ }^{\circ} \mathrm{C}$ until extraction within $12 \mathrm{~h}$. Dewatered sludge samples were homogenized on site and stored in clean stainless-steel containers, then immediately sealed and stored at $4^{\circ} \mathrm{C}$ until analysis. Sampling sites of water samples included influent, second sedimentation tank effluent, the flocculation, and the filtration. Water samples were taken monthly from October 2006 to September 2007. Detailed sampling information is shown in Table 1.

Chemicals and materials

The target steroidal estrogen compounds for this study included three natural estrogens, specifically estrone (E1), $\beta$-estradiol (E2), and estriol (E3), and one synthetic estrogen, $17 \alpha$-ethynylestradiol (EE2). All target compounds were of the highest purity commercially available. The E1, E2, and EE2 were purchased from Sigma-Aldrich, Milwaukee, WI, USA, while E3 was purchased from Flucka, Chemie B.V., Zwijndrecht, The Netherlands. Derivatization reagents of bis(trimethyl)-trifluoroacetamide (BSTFA) containing $1 \%$ of trimethylchlorosilane (TCMS) and trimethylsilylimidazole (TMSI) were purchased from Supelco, Bellefonte, PA, USA, and Sigma-Aldrich, Chemie, Gmbh, Germany, respectively. Surrogate standard 17- $\beta$-estradiol-16, 16, 17- $\mathrm{d}_{3}\left(\mathrm{E} 2-\mathrm{d}_{3}\right)$ was produced by $\mathrm{C} / \mathrm{D} / \mathrm{N}$ Isotopes (Pointe-Claire, $\mathrm{QC}$, Canada). Internal standard pyrene- $\mathrm{d}_{16}$ was purchased from Supelco, Bellefonte, PA, USA. Acetone, nhexane, dichloromethane (DCM), methanol $(\mathrm{MeOH})$, ethyl acetate, and cyclohexane were of highperformance liquid chromatography (HPLC) grade and were purchased from Mallinckrodt, USA. Sodium sulfate (analytical reagent grade, Mallinckrodt, USA) was sequentially rinsed with acetone, DCM, and

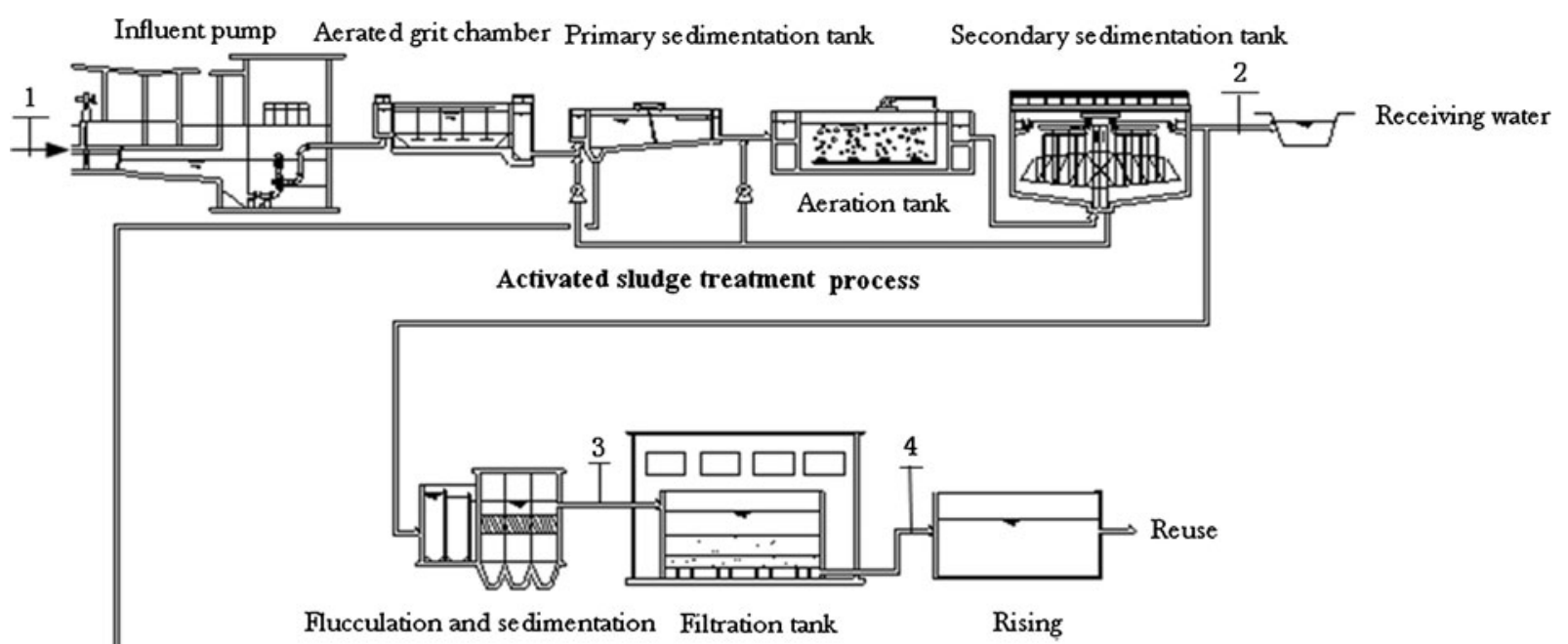

Teritary treatment process

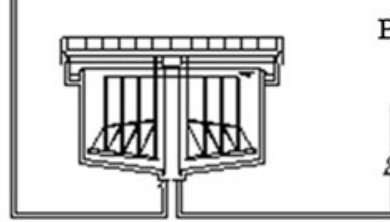

Thickener

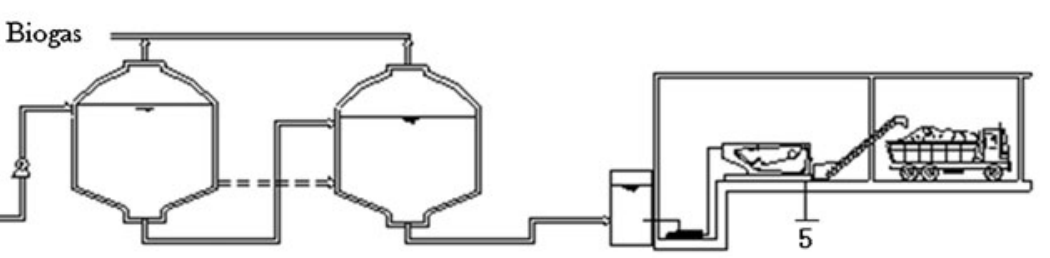

Digester
Dewatered sludge

Sludge treatment process

Fig. 1 Plot of the wastewater treatment plant and sampling points 
Table 1 Information of sampling time, sample types, and sampling sites

\begin{tabular}{|c|c|c|c|c|c|c|c|c|c|c|c|}
\hline \multirow[t]{2}{*}{ Time } & \multirow[t]{2}{*}{ Weather } & \multirow[t]{2}{*}{ Temperature $\left({ }^{\circ} \mathrm{C}\right)$} & \multicolumn{2}{|c|}{ Influent } & \multicolumn{2}{|c|}{$\begin{array}{l}\text { Secondary } \\
\text { sedimentation } \\
\text { effluent }\end{array}$} & \multicolumn{2}{|c|}{$\begin{array}{l}\text { Flocculation } \\
\text { effluent }\end{array}$} & \multicolumn{2}{|c|}{$\begin{array}{l}\text { Filtration } \\
\text { effluent }\end{array}$} & \multirow[t]{2}{*}{$\begin{array}{l}\text { Dewatered } \\
\text { sludge }\end{array}$} \\
\hline & & & Water & SS & Water & SS & Water & SS & Water & SS & \\
\hline Oct-14th-2006 & Fog & $15-22$ & $\sqrt{ }$ & & $\sqrt{ }$ & & $\sqrt{ }$ & & $\sqrt{ }$ & & \\
\hline Nov-14th-2006 & Sunny & $0-13$ & $\sqrt{ }$ & & $\sqrt{ }$ & & $\sqrt{ }$ & & $\sqrt{ }$ & & \\
\hline Dec-14th-2006 & Cloudy, sunny & -3 to 5 & $\sqrt{ }$ & & $\sqrt{ }$ & & $\sqrt{ }$ & & $\sqrt{ }$ & & \\
\hline Jan-29th-2007 & Sunny & -5 to 3 & $\sqrt{ }$ & & $\sqrt{ }$ & & $\sqrt{ }$ & & $\sqrt{ }$ & & \\
\hline Mar-9th-2007 & Cloudy, sunny & -4 to 3 & $\sqrt{ }$ & & $\sqrt{ }$ & & $\sqrt{ }$ & & $\sqrt{ }$ & & \\
\hline Mar-29th-2007 & Cloudy & $6-15$ & $\sqrt{ }$ & & $\sqrt{ }$ & & $\sqrt{ }$ & & $\sqrt{ }$ & & \\
\hline Apr-26th-2007 & Sunny & $10-24$ & $\sqrt{ }$ & & $\sqrt{ }$ & & $\sqrt{ }$ & & $\sqrt{ }$ & & \\
\hline May-23rd-2007 & Shower, cloudy & $18-31$ & $\sqrt{ }$ & & $\sqrt{ }$ & & $\sqrt{ }$ & & $\sqrt{ }$ & & \\
\hline Jun-28th-2007 & Sunny, thunder shower & $23-29$ & $\sqrt{ }$ & & $\sqrt{ }$ & & $\sqrt{ }$ & & $\sqrt{ }$ & & \\
\hline Jul-28th-2007 & Cloudy & $22-31$ & $\sqrt{ }$ & & $\sqrt{ }$ & & $\sqrt{ }$ & & $\sqrt{ }$ & & \\
\hline Aug-28th-2007 & Light rain & $20-27$ & $\sqrt{ }$ & $\sqrt{ }$ & $\sqrt{ }$ & $\sqrt{ }$ & $\sqrt{ }$ & $\sqrt{ }$ & $\sqrt{ }$ & $\sqrt{ }$ & $\sqrt{ }$ \\
\hline Sep-27th-2007 & Cloudy & $13-22$ & $\sqrt{ }$ & & $\sqrt{ }$ & & $\sqrt{ }$ & & $\sqrt{ }$ & & \\
\hline Oct-25th-2007 & Fog & $9-18$ & $\sqrt{ }$ & & $\sqrt{ }$ & & $\sqrt{ }$ & & $\sqrt{ }$ & & \\
\hline
\end{tabular}

SS suspension solid

hexane three times each, and completely dried in the fume hood. The dried sodium sulfate was baked at $450^{\circ} \mathrm{C}$ for $4 \mathrm{~h}$ and stored in an airer. The silica gel (60-200 mesh, Acros Organics, Fair Lawn, NJ, USA) and neutral alumina (50-200 mesh, Acros Organics, Fair Lawn, NJ, USA) were activated at $180^{\circ} \mathrm{C}$ and $250^{\circ} \mathrm{C}$ for $12 \mathrm{~h}$, respectively, and then stored in an airer. All glassware were firstly treated with sulphochromic mixtures and then washed successively with deionized water, HPLC grade acetone, and hexane before use.

A stock solution of all target chemicals in a concentration of $10 \mathrm{mg} / \mathrm{ml}$ was prepared in methanol and stored in an amber glass vial at $-20^{\circ} \mathrm{C}$. The working solutions for the individual standards and their mixtures were achieved by serial dilution of stock solutions with pure $n$-hexane. These solutions were stored at $4^{\circ} \mathrm{C}$.

Analytical procedures

\section{Pretreatment of water samples}

Pretreatment of water samples was modified according to a previous study (Zhou et al. 2009). Water samples (the WWTP influent sample 0.51 , other sample 2.01 ) were pre-filtered using $0.45-\mu \mathrm{m}$ APFF fiberglass filters (Millipore, Bedford, MA, USA) to eliminate particulate matter, then spiked with surrogate standard $\left(\mathrm{E} 2-\mathrm{d}_{3}\right)$ and adjusted to $\mathrm{pH} 3.0-4.0$ using hydrochloric acid before extraction. The Oasis HLB cartridges were conditioned with $5 \mathrm{ml}$ of tertbutyl methyl ether, $5 \mathrm{ml}$ of methanol, and $5 \mathrm{ml}$ of DI water. Water samples were passed through the cartridges at a flow rate of $10 \mathrm{ml} / \mathrm{min}$. The cartridges were prevented from drying out during loading of the water sample. The cartridge was then washed with $5 \mathrm{ml}$ of methanol/water $(25 / 75, v / v), 5 \mathrm{ml}$ of DI water, and $5 \mathrm{ml}$ of methanol/ammonia/DI water (10/2/88, $v / v)$, followed by vacuum to dry. Subsequently, $10 \mathrm{ml}$ of methanol/tert-butyl methyl ether $(1 / 9, v / v)$ was used for elution of the SPE cartridges. Elution was gathered by the KD concentrator, dehydrated by anhydrous sodium sulfate, and then dried to $0.5 \mathrm{ml}$ under a gentle stream of high purity nitrogen in a $40^{\circ} \mathrm{C}$ water bath. Concentrated solution was clarified using a 5-g silica gel and 5-g neutral alumina filling column, which was wet packed using $n$ hexane as the solvent. Approximately $2 \mathrm{ml}$ of methanol/acetone (50:50) was used to wash the $\mathrm{KD}$ concentrator and then transferred to the filling column. The filling column was eluted with $10 \mathrm{ml}$ of methanol/acetone (50:50). The elution reduced the 
volume to dryness under a gentle stream of high purity nitrogen gas.

\section{Pretreatment of suspended solid and dewatered sludge}

A freeze-dried filter containing suspension solid or $10 \mathrm{~g}$ of sludge was put into a $50-\mathrm{ml}$ amber glass vial with polytetrafluoroethylene screw cap and then sonicated with $15 \mathrm{ml}$ of hexane/acetone $(1: 1, v / v)$ in an ultrasonic bath (Institute of Acoustics, CAS, China) for $20 \mathrm{~min}$. The slurry was then centrifuged at $825 \times \mathrm{g}$ for $5 \mathrm{~min}$, and the supernatants were collected. The sonication was performed three times, and the extract was combined. The extract was then reduced to $0.5 \mathrm{ml}$ by rotary evaporator (Buchi Rotavpor R-200, Flawil, Switzerland) and a gentle flow of high purity nitrogen gas. The concentrated extract was dissolved in $10 \mathrm{ml}$ of ethyl acetate/ cyclohexane $(1: 1, v / v)$ and injected into the GPC column (CO785, Accuprep MPSTM, J2 Scientific, Columbia, USA) to remove matrix components with high molecular masses (J1000amu) (Ternes et al. 2002). A mixture of ethyl acetate/cyclohexane (1:1, $v / v$ ) was used as the eluent, and the flow rate was adjusted to $4.7 \mathrm{ml} / \mathrm{min}$. The first fraction from 0 to 8 min, which contained higher molecular weight compounds, was discarded. The second fraction containing the estrogens was collected from between 8 and $20 \mathrm{~min}$. Elution of the second fraction was reduced to $0.5 \mathrm{ml}$ by rotary evaporator and a gentle flow of high purity nitrogen gas. The following purification was performed by silica gel and neutral alumina chromatographic column. The activated silica gel and neutral alumina were partially deactivated with $3 \%$ water $(w / w)$ and immersed in hexane. A chromatographic column with a Teflon stopcock (200-10.5 mm I.D.) was plugged with glass wool at the bottom and then half filled with hexane. The column was wet-packed successively with $4 \mathrm{~cm}$ deactivated silica gel, $4 \mathrm{~cm}$ deactivated neutral alumina, and $2 \mathrm{~cm}$ anhydrous sodium sulfate. The column was tapped to settle the silica gel and alumina. The concentrated extract after GPC cleanup was transferred carefully to the prepared compound column of silica gel and alumina using pipette. The analytes were eluted successively using $10 \mathrm{ml}$ of hexane, $20 \mathrm{ml}$ of hexane/acetone $(65: 35, v / v)$, and
$40 \mathrm{ml}$ of acetone/methanol $(1: 1, v / v)$. Four steroidal estrogens were in the acetone/methanol fraction. The acetone/methanol eluate was collected and then evaporated to just dryness.

\section{Derivatization and instrumental analysis}

The derivatization and analytical conditions of the target compounds are described in previous research (Zhou et al. 2009). Briefly, the residues of water sample extractions, the suspended solid extractions, and the dewatered sludge extractions were redissolved in $0.4 \mathrm{ml}$ of hexane that contained $50 \mu \mathrm{l}$ of the derivatization mixture BSTFA/TCMS/TMSI (99:1:0.5, $v / v / v)$ and $50 \mathrm{ng} / \mathrm{ml}$ of pyrene- $\mathrm{d}_{16}$. The derivatization was performed at $60^{\circ} \mathrm{C}$ for $30 \mathrm{~min}$. The derivatives were cooled to room temperature and stored at $4^{\circ} \mathrm{C}$. Instrumental analysis was performed within 2 days.

The separation and detection of the target compounds was achieved by gas chromatography-mass spectrometry (Agilent 6890 with mass spectrometer Agilent 5973 MSD, Agilent Technologies, Englewood, CO, USA). System control and data acquisition were achieved with ChemStation Software. One microliter of derivatives was injected into the HP-5 MS column $(30 \mathrm{~m} \times 0.25 \mathrm{~mm} \times 0.25 \mu \mathrm{m}$ film thickness) in splitless mode. Helium (99.9999\%) was used as the carrier gas, with the flow rate set at $1 \mathrm{ml} / \mathrm{min}$. Gas chromatographic temperature programs were as follows: initial temperature of $80^{\circ} \mathrm{C}$ held for $1 \mathrm{~min}$, increased to $200^{\circ} \mathrm{C}$ at a rate of $20^{\circ} \mathrm{C} / \mathrm{min}$, then increased to $300^{\circ} \mathrm{C}$ at a rate of $10^{\circ} \mathrm{C} / \mathrm{min}$ and held for $10 \mathrm{~min}$, with a total run of $27 \mathrm{~min}$ and solvent delay of $6 \mathrm{~min}$. The injector and detector temperatures were set at $280^{\circ} \mathrm{C}$. The ion source temperature was $230^{\circ} \mathrm{C}$, and the energy of the ionizing electron was $70 \mathrm{eV}$.

Quality assurance and quality control

All data were subject to strict quality control procedures. Before analysis, relevant standards were run to check column performance, peak height, resolution, and sensitivity. With each set of samples analyzed, a solvent blank, a procedural blank, and a standard mixture of four estrogens were run in sequence to check contamination, peak identification, and quantification. No target compound was detected in the procedural blanks. Qualitative analysis of the 
target compounds was accomplished on the basis of retention time and mass spectrum in a full scan model. Characteristic ions/quantification ions for each substance were 212 and 106/212 for pyrene-d16, 342, 218, and 257/342 for E1, 416, 285, and 129/416 for E2, 419 for E2-d3, 425, 285, and 440/425 for EE2, and 504, 129, and 345/504 for E3, respectively. Quantitative analysis was performed in ion monitoring (SIM) mode using internal standard calibration. Initially, a series of target compound injections in the concentration range of $0.5-1,000 \mathrm{ng} / \mathrm{ml}$ with constant internal standard $(50 \mathrm{ng} / \mathrm{ml})$ were performed to determine linear concentration range. Good linearity was observed with correlation coefficients above 0.99 . Calibration curves were obtained by linear regression analysis to calculate unknown concentration.

Limit of detection (LOD) and limit of quantification (LOQ) for water samples were achieved by 1,250 and 5,000 times concentration for influent and effluent from the WWTP. Both were calculated as the minimum amount of compound present in the sample that produced a signal/noise ratio of 3 and 6 , based on an injection of $1 \mu \mathrm{l}$ aliquot of the final $0.4 \mathrm{ml}$ extraction solution (Zhou et al. 2009). For sludge, LOD and LOQ were determined on the basis of $10 \mathrm{~g}$ of sludge to $0.4 \mathrm{ml}$ solution. The LOD and LOQ in water were $0.1-0.5$ and $1.2-3.6 \mathrm{ng} / \mathrm{l}$ for influent and $0.1-0.3$ and $0.1-0.8 \mathrm{ng} / \mathrm{l}$ for effluent, respectively. For dried sludge, they were 0.1 and $0.1-$ $0.2 \mathrm{ng} / \mathrm{g}$, respectively. A recovery study was performed on samples spiked with known levels of the estrogens (100 ng/l for influent, $10 \mathrm{ng} / \mathrm{l}$ for effluent, and $10 \mathrm{ng} / \mathrm{g}$ for sludge). Mean recoveries of estrogens were $78.9-108.0 \%$ for influent, $66.6-121.1 \%$ for effluent, and $46.5-97.6 \%$ for dried sludge. Relative standard deviation was $2.7-6.4 \%, 1.5 \%-4.7 \%$, and $1.8-5.1 \%$ for influent, effluent, and dried sludge, respectively.

\section{Calculations}

In influent, the organic carbon $\left(K_{\mathrm{oc}}\right)$ partition coefficient was defined as Eq. 1:

$K_{\mathrm{oc}}=K_{\mathrm{d}} / f_{\mathrm{oc}}, K_{\mathrm{d}}=\left(C_{\mathrm{s}} \times 1,000 / C_{\mathrm{aq}}\right)$

where $C_{\mathrm{s}}$ is the solid phase concentration (ng/g), $C_{\mathrm{aq}}$ is the aqueous phase concentration (ng/l), $f_{\mathrm{oc}}$ is organic carbon fraction (\%) of suspended solid, and $K_{\mathrm{d}}$ is the adsorption coefficient $(1 / \mathrm{kg})$.

For the WWTP, the removal obtained was calculated from the aqueous analyte concentration in raw sewage water $\left(C_{\text {inf }}\right)$ and final effluent $\left(C_{\text {eff }}\right)$ according to Eq. 2:

Removal $(\%)=\left[\left(C_{\text {inf }}-C_{\text {eff }}\right) \times 100\right] / C_{\text {inf }}$

In addition, the mass load of estrogens lost due to the sum of all transformation processes $\left(W_{\text {lost }}\right)$ was calculated according to Eq. 3:

$W_{\text {lost }}=\left(Q_{\text {in }} \times C_{\text {in }}\right)-\left(Q_{\text {out }} \times C_{\text {out }}\right)-W_{\text {sludge }}$

where $Q_{\text {in }}$ and $Q_{\text {out }}$ are the flow rates of the influent $\left(\mathrm{m}^{3} /\right.$ day $)$ and the effluent $\left(\mathrm{m}^{3} /\right.$ day), respectively, $C_{\text {in }}$ and $C_{\text {out }}$ are the total estrogen concentrations (sum of dissolved and particulate) in influent and effluent, respectively, and $W_{\text {sludge }}$ is the mass output of estrogens in dewatered digested sludge (g/day).

Mass flows, in grams per day, of individual estrogens were calculated from concentrations of the sampling event in each matrix using the corresponding mean daily wastewater volume and the corresponding mean daily sludge production.

\section{Results and discussion}

Levels of steroid estrogens in WWTP influent and effluent

Analysis results of the four steroid estrogens in the WWTP water samples are summarized in Table 2. In influent, steroid estrogen concentrations varied from 11.6 to $1.1 \times 10^{2} \mathrm{ng} / 1,3.7$ to $1.4 \times 10^{2} \mathrm{ng} / \mathrm{l}$, no detection (nd) to $7.6 \times 10^{2} \mathrm{ng} / \mathrm{l}$, and nd to $3.3 \times$ $10^{2} \mathrm{ng} / 1$ for E1, E2, E3, and EE2, respectively, with mean concentrations of $66.8,44.7,2.6 \times 10^{2}$ and $48.0 \mathrm{ng} / \mathrm{l}$. In effluent, steroid estrogen concentrations varied from 0.2 to $74.2 \mathrm{ng} / \mathrm{l}$, nd to $8.4 \mathrm{ng} / \mathrm{l}$, nd to $6.6 \mathrm{ng} / \mathrm{l}$, and nd to $5.1 \mathrm{ng} / \mathrm{l}$ for E1, E2, E3, and EE2, respectively, with mean concentrations of 12.7, 1.7, 1.9 , and $2.0 \mathrm{ng} / \mathrm{l}$. Previous research determined mean influent concentrations for E1, E2, E3, and EE2 of nd to $66.0 \mathrm{ng} / 1$, nd to $22.7 \mathrm{ng} / \mathrm{l}$, nd to $80.0 \mathrm{ng} / \mathrm{l}$, and nd to $7.1 \mathrm{ng} / \mathrm{l}$, respectively (Baronti et al. 2000; Fawell et al. 2001; Johnson and Sumpter 2001; D'Ascenzo et al. 2003; Cargouët et al. 2004). In WWTP effluent, 
Table 2 Concentrations of E1, E2, E3, and EE2 in aqueous phase (ng/l)

\begin{tabular}{|c|c|c|c|c|c|c|c|c|c|c|c|c|c|c|c|c|}
\hline & \multicolumn{4}{|c|}{ Compound influent } & \multicolumn{4}{|c|}{ Secondary sedimentation effluent } & \multicolumn{4}{|c|}{ Flocculation effluent } & \multicolumn{4}{|c|}{ Filtration effluent } \\
\hline & Min & Max & Median & Mean & Min & $\operatorname{Max}$ & Median & Mean & Min & Max & Median & Mean & Min & Max & Median & Mean \\
\hline E1 & 11.6 & $1.1 \times 10^{2}$ & 79.8 & 66.8 & 0.2 & 74.2 & 5.7 & 12.7 & nd & $2.3 \times 10^{2}$ & 7.5 & 35.7 & nd & $1.4 \times 10^{2}$ & 5.3 & 15.2 \\
\hline E2 & 3.7 & $1.4 \times 10^{2}$ & 24.5 & 44.7 & nd & 8.4 & 1.0 & 1.7 & nd & 10.8 & 1.0 & 2.8 & nd & 8.4 & 1.0 & 1.9 \\
\hline E3 & nd & $7.6 \times 10^{2}$ & $2.2 \times 10^{2}$ & $2.6 \times 10^{2}$ & nd & 6.6 & 1.4 & 1.9 & nd & 10.6 & 2.7 & 3.8 & nd & 11.0 & 1.0 & 2.4 \\
\hline EE2 & nd & $3.3 \times 10^{2}$ & 31.8 & 48.0 & nd & 5.1 & 1.7 & 2.0 & nd & 6.5 & 1.4 & 1.9 & nd & 5.8 & 1.5 & 1.9 \\
\hline
\end{tabular}

nd No detection

values of nd to 82 , nd to $64,0.4$ to $39.1 \mathrm{ng} / \mathrm{l}$ and nd to 42 for E1, E2, E3, and EE2 have been detected in The Netherlands (Vethaak et al. 2005), Italy (Baronti et al. 2000), the UK (Desbrow et al. 1998; Johnson et al., 2001), Germany and Canada (Ternes et al. 1999b), Sweden (Larsson et al. 1999), Japan (Nakada et al. 2007), and China (Chen et al. 2007; Jin et al. 2008). Influent concentrations of steroid estrogens in this study were higher than previous reports, particularly for E3 and EE2. Previous research has shown E3 is excreted mainly by pregnant women (D'Ascenzo et al. 2003). In addition, EE2 is the main ingredient of the contraceptive pill, with an average daily dose of $35 \mu \mathrm{g}$ taken for 21 of a 28-day cycle (Ranney 1977; Maggs et al. 1983; Katzung 1995). The higher influent concentration of estrogens in the present study may be due to a higher population density and birthrate in Beijing. Other factors including sampling time and individual water consumption are also very important. We collected samples between 9 and 11 o'clock; however, previous research has reported that highest estrogenic activities appeared at 10 o'clock in WWTP effluent from the USA (Martinović et al. 2008). Chang et al. (2011) reported a lower influent concentration of E1 and E2, which was determined according to $24 \mathrm{~h}$ composite samples. It provided indirect evidence that we taken samples during the higher concentration period. Based on an average wastewater production of 2001 per person per day, the maximum estimated concentration of natural estrogens and synthetic estrogen EE2 are 1,000 and $13.4 \mathrm{ng} / \mathrm{l}$, respectively (Blok and Wösten 2000). Considering floating populations, average water consumption is $<1501$ per person per day in Beijing (Beijing Statistical Yearbook 2006), which indicates that human excretion containing steroid estrogen was less diluted in the Beijing WWTP wastewater. Compared with previous research, however, the effluent concentrations of the steroid estrogens in this study are relatively lower, except for E1. This indicated that the selected WWTP was more effective at eliminating steroid estrogen pollution.

As shown in Fig. 2, for influent, E1 and E3 were the main contributors and accounted for $>60 \%$. Because only $1-2 \%$ of administered EE2 is transformed to E1, E2, or E3 (Ranney 1977) and, compared with natural E2 excretion, the amount of E2 in pharmaceutical usage is $<5 \%$ (Christensen 1998), the higher relative abundance of natural estrogens should be due to human excretions (Zhou et al. 2011). A study in Japan has also concluded that human estrogens are the major estrogenic compounds in sewage and effluent (Matsui et al. 2000). In effluent from the present study, the relative abundance of $\mathrm{E} 1$ and $\mathrm{EE} 2$ in excess of $70 \%$ revealed lower removal of E1 and EE2. Baronti et al. (2000) reported removal of E1, E2, E3, and EE2 at $61 \%, 87 \%, 95 \%$, and $85 \%$ in an activated sludge treatment plant. Their lower elimination efficiencies for E1 and EE2 are consistent with our results.

The distributions of steroid estrogens between the aqueous phase and suspended solids in the influent were investigated using an influent sample collected on August 28, 2007. From Fig. 3, it can be seen that the adsorbed portions of steroid estrogens were $1.5 \%$, $96.4 \%, 18.0 \%$, and $38.8 \%$ for E3, E1, EE2, and E2, respectively. The adsorbed portion of the steroid estrogens increased with increasing octanol-water partition coefficients $\left(\log K_{\mathrm{ow}}\right)$, except for E1. $\log K_{\mathrm{ow}}$ values for E1, E2, E3, and EE2 of 3.13, 4.01, 2.45, and 3.67, respectively, have been previously reported (Kuster et al. 2004, 2005). A function relationship between organic carbon $\left(K_{\mathrm{oc}}\right)$ partition coefficients and octanol-water $\left(K_{\mathrm{ow}}\right)$ coefficients has also been reported (Means et al. 1982), although surface characteristics of the solid and the transformation of 

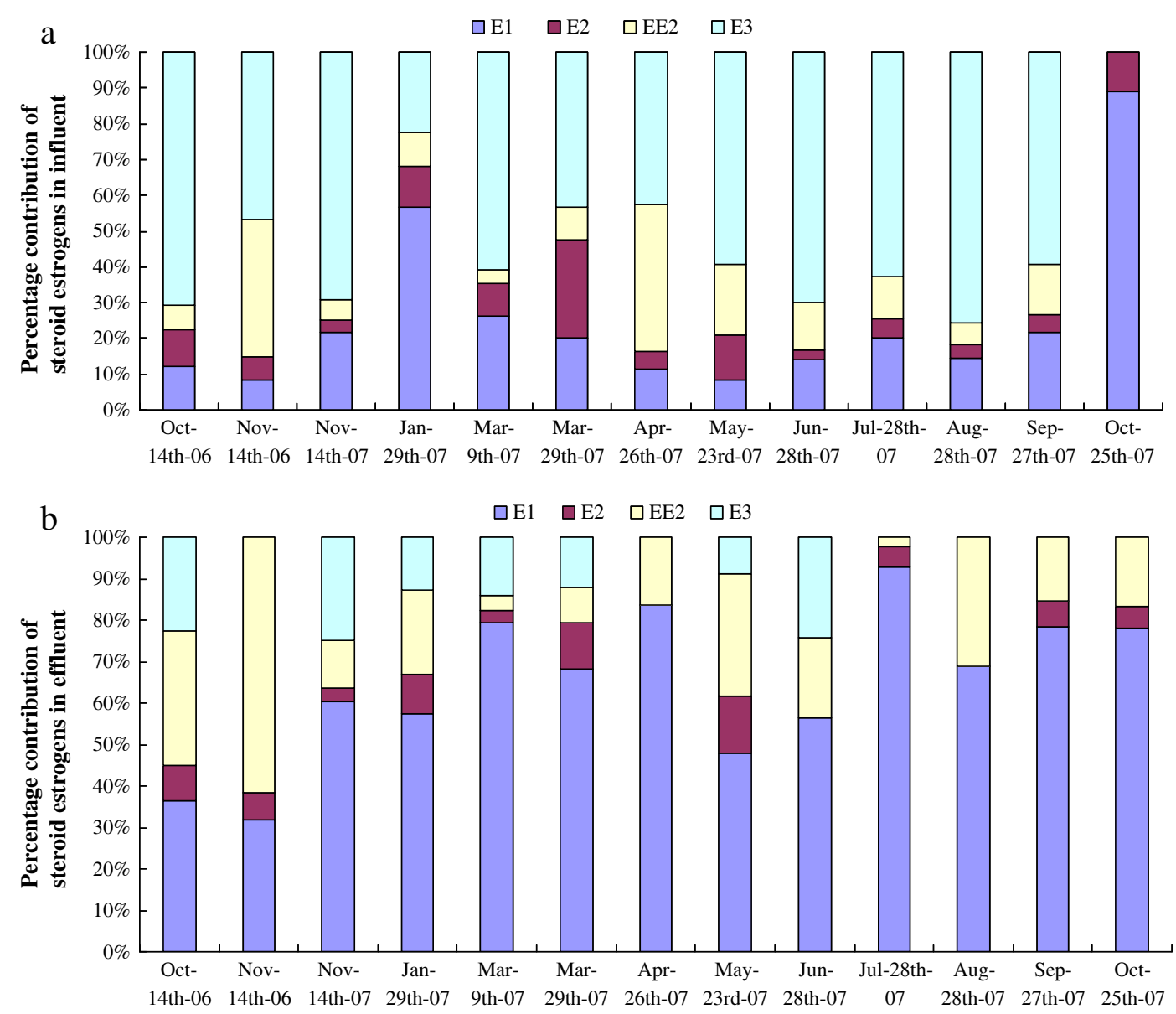

Fig. 2 Relative abundance of steroid estrogens in influent (a) and effluent (b) of the WWTP at different time

target compounds in the activated solid were not considered. Lei et al. (2009) demonstrated a good coefficient relationship between $K_{\mathrm{oc}}$ and $K_{\mathrm{ow}}$ for steroid estrogens in river sediments, which may be due to anaerobic sediment conditions where estrogen degraded slowly. However, in the present study, the $\log K_{\mathrm{oc}}$ of E1, E2, E3, and EE2 was 4.50, 2.87, 1.26, and 2.41, respectively. Comparatively, the $\log K_{\mathrm{oc}}$ of E1 was one order of magnitude greater than demonstrated in previous literature (3.10-4.18); however,
Fig. 3 Distribution of steroid estrogens in aqueous phase and suspension solid of the influent (the $\log K_{\mathrm{ow}}$ values are $2.45,3.13,3.67$, and 4.01 for E3, E1, EE2, and E2 respectively)

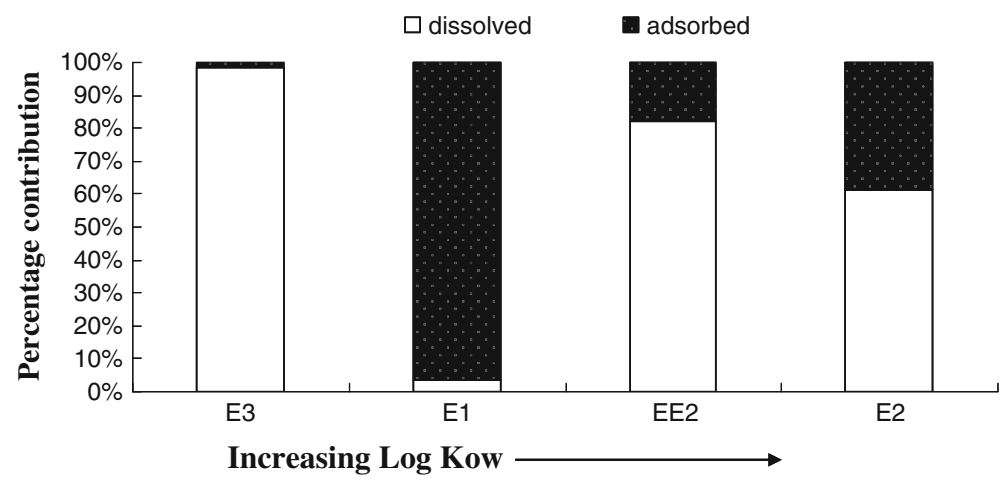


the $\log K_{\mathrm{oc}}$ values of E2, E3, and EE2 were one order of magnitude smaller $(3.30-3.69,2.23-2.50$, and 3.31-4.16 for E2, E3, and EE2) (Lai et al. 2000; Clara et al. 2004; Carballa et al. 2008). A possible explanation is that E2 and EE2 particulates were adsorbed on suspended solids and transformed to E1, with the relatively longer sewers entering WWTPs in Beijing providing enough reaction time.

The total amount of the four steroid estrogens in the solid phase was about four times that in the aqueous phase, which may be due to the special surface characteristics of the solid and water parameter in the WWTP. Estrogenic activity has also been found particularly high in the suspended solid fraction from a biosolid treatment facility (David et al. 2002). This indicates that it is possible for higher level estrogens to occur in suspended solids of municipal wastewater.

Seasonal concentration variation of steroid estrogens in WWTP influent and effluent

To understand seasonal variation in distribution levels and elimination efficiency of steroid estrogens in the WWTP, influent and effluent samples were collected and analyzed monthly from October 2006 to September 2007. According to the atmospheric temperature in Beijing and WWTP wastewater temperature (data not shown), the year was divided into distinct winter, spring, summer, and autumn seasons. The periods of December to February (atmospheric temperature below $0^{\circ} \mathrm{C}$ and water temperature below $15^{\circ} \mathrm{C}$ ), March to May (atmospheric temperature between $5^{\circ} \mathrm{C}$ and $20^{\circ} \mathrm{C}$ and water temperature between $15^{\circ} \mathrm{C}$ and $20^{\circ} \mathrm{C}$ ), June to August (atmospheric temperature between $25^{\circ} \mathrm{C}$ and $30^{\circ} \mathrm{C}$ and water temperature between $25^{\circ} \mathrm{C}$ and $28^{\circ} \mathrm{C}$ ), and September to November (atmospheric temperature between $10^{\circ} \mathrm{C}$ and $22^{\circ} \mathrm{C}$ and water temperature between $15^{\circ} \mathrm{C}$ and $25^{\circ} \mathrm{C}$ ) were defined as winter, spring, summer, and autumn. The concentration levels and percentage removal rates of steroid estrogens in the WWTP are illustrated in Fig. 4. The mean influent concentrations of E1 were $70.3 \pm 35.9,85.7 \pm 19.9,65.8 \pm 39.7$, and $66.2 \pm 8.8 \mathrm{ng} / \mathrm{l}$ in winter, spring, summer, and autumn, respectively. The mean influent concentrations of E2 were $18.6 \pm 14.3,102.8 \pm 67.1,16.8 \pm 11.4$, and $43.4 \pm$ $27.1 \mathrm{ng} / \mathrm{l}$ in winter, spring, summer, and autumn, respectively. For EE2, the mean influent concentrations were $11.8 \pm 3.8,105.7 \pm 104.8 .1,36.5 \pm 17.8$, and126.0 $\pm 148.9 \mathrm{ng} / \mathrm{l}$ in winter, spring, summer, and autumn, respectively. For E3, the mean influent concentrations were $116.6 \pm 95.7,374.5 \pm 261.9$, $275.8 \pm 166.4$, and $323.2 \pm 147.6 \mathrm{ng} / \mathrm{l}$ in winter, spring, summer, and autumn, respectively. Among the three natural estrogens, the higher abundance of E3 and E1 may be due to two reasons. First, E1 is the most abundant estrogen excreted by menstrual women, and the second is that E3 and E1 in pregnancy urine are one and two orders of magnitude greater than E2 (Baronti et al. 2000). A similar result has been reported in a municipal sewage treatment plant in Wuhan, China (Jin et al. 2008). The relatively high influent concentration of EE2 in our studied WWTP may be due to correlative industry discharge (Cui et al. 2006; Zhou et al. 2011) or/and different consumption rates of contraceptive pills compared to other regions. For steroid estrogens E2, E3, and EE2, the seasonal influent concentration was in the order of spring $>$ autumn $>$ summer $>$ winter. However, a different result was found in a municipal sewage treatment plant in Wuhan, China (Jin et al. 2008), which showed higher influent concentration of E3 in winter than summer.

In general, the influent concentrations of each estrogen in our selected WWTP were higher than previously documented values (Baronti et al. 2000; Jin et al. 2008). The higher influent concentration of steroid estrogen in summer in the present WWTP can be explained by the hypothesis that influent concentrations were impacted by human excretion rates, water consumption, and rainfall. Another possible explanation is that natural estrogens rapidly degrade at high temperature in summer (Layton et al. 2000). Generally, water consumption, rainfall, and degradation increase in summer due to higher temperatures. These will, in turn, lead to a decrease in influent concentration of steroid estrogens. Therefore, the higher influent concentration of steroid estrogen in summer may be due to rapid human excretion. Of course, because industrial wastewater amounts to $50 \%$ of the total collection volume in the selected WWTP, the industrial discharge volume should not be ignored. In addition, as pregnant women are the primary contributors of natural estrogen in municipal wastewater, the variation of pregnant women populations also deserves attention.

The sum of the effluent concentrations of E1, E2, E3, and EE2 were $19.2 \pm 13.6,16.4 \pm 6.1,32.0$ 
Fig. 4 The influent concentrations, effluent concentrations and removal rates of estrogen in different seasons
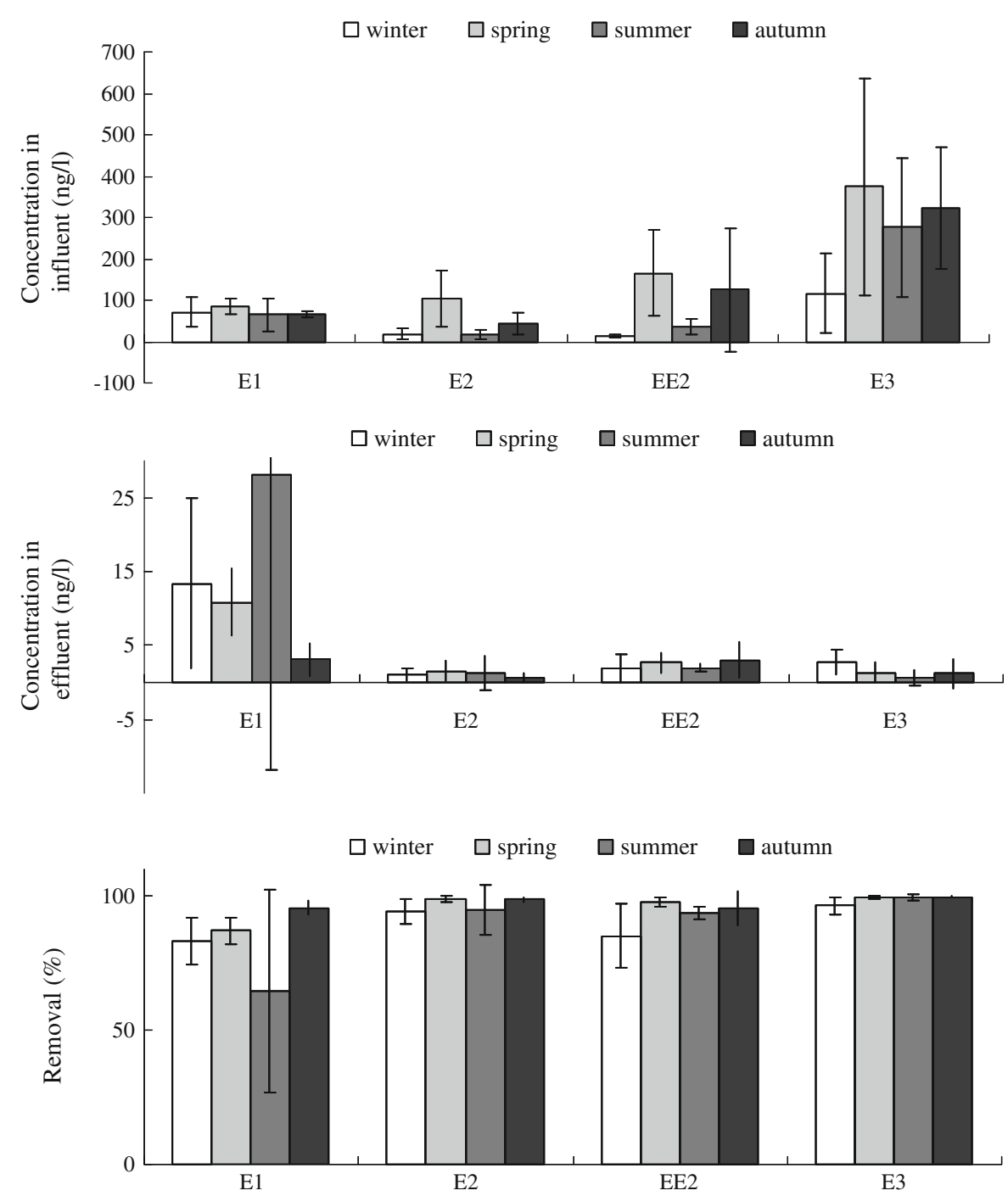

\pm 41.6 , and $7.9 \pm 7.1 \mathrm{ng} / \mathrm{l}$ in winter, spring, summer, and autumn, respectively. In effluent, E1 was the most abundant of the four steroid estrogens. The relatively high effluent concentration of E1 occurred in summer, which was due to the higher water temperature quickening the transformation step of estrone sulfate to free estrone. Previous research has reported that $36 \%$ of estrone sulfate, $16 \%$ of estrone glucuronides, and estriol glucuronide passed through the treatment system and entered receiving water (D'Ascenzo et al. 2003). These residual estrogen conjugates may transform to corresponding free estrogens at different efficiencies under different ambient conditions, which influences the effluent concentration of these corresponding free estrogens.
The removal rates of the steroid estrogens were $71.3-98.6 \%, 84.1-100 \%, 21.9-100 \%$, and $88.1-$ $100 \%$ in winter, spring, summer, and autumn, respectively (Fig. 4). The estrogen removal efficiency of sewage wastewater treatment plants is influenced by microbial activity, sludge retention time, hydraulic retention time, temperature, and rainfall, which all vary seasonally (Ternes 1998). As a whole, higher and steady removal rates were present in autumn. The highest and the lowest removal were for E3 and E1, respectively. Mean percentage elimination efficiencies were $83.2 \%, 96.4 \%, 98.8 \%$, and $93.0 \%$ with relative standard deviation of $20.4 \%, 5.0 \%$, $2.1 \%$, and $7.7 \%$ for E1, E2, E3, and EE2, respectively. Baronti et al. (2000) investigated six sewage 
wastewater treatment plants and found average removal rates of $87 \pm 9 \%, 95 \pm 6 \%$, and $85 \pm 14 \%$ for E2, E3, and EE2, respectively, but lower average removal rates of $61 \pm 38 \%$ for E1 and zero removal in four out of 30 events. Jin et al. (2008) reported mean removal rates of $65.8,78.7$, and 99.0 for E1, E2, and E3, respectively. The present study showed similar results with previous investigations. The selected municipal WWTP with an activated sludge system incorporating anaerobic, anoxic, and aerobic processes effectively eliminated the natural and synthetic estrogens.

Although higher elimination efficiency of the target compounds was achieved in the WWTP, it is still essential to add advanced processes to remove residual pollution in the effluent for water reuse. In the WWTP, flocculation and sand filtration were applied to reduce residual contamination in the effluent. To meet environmental protection laws, the basic goal was to reduce residual nitrogen and phosphorus. As far as we know, no steroid estrogen assessment has been preformed previously in China. From Table 2, the mean concentrations in the flocculation process effluent were $35.7,2.8,3.8$, and $1.9 \mathrm{ng} / \mathrm{l}$ for E1, E2, $\mathrm{E} 3$, and EE2, respectively. In most cases, the concentrations of the steroid estrogens in the flocculation process effluent were greater than in the effluent from the secondary setting tank. This indicated that the flocculation process applied in the WWTP may transform residual estrogen conjugates to their free species. The estrogens may be further reduced by filtration, with removal shifting from $32 \%$ to $57 \%$ for natural estrogen, although no EE2 was removed. Sand filters are often applied to reduce contamination by flocculation particulates, so it was important that contaminants were adsorbed by flocculation before filtering. Previous research has shown that coagulation does not enhance removal efficiency of estrogen in full treatment plants and batch tests (Johnson et al. 2000; Ong et al. 2001). As the WWTP effluent concentrations of the steroid estrogens are enough to produce adverse effects on wild animals (Routledge et al. 1998; Rodgers-Gray et al. 2000; Zha et al. 2008), other advanced processes such as activated carbon and oxidation should be considered to remove residual steroid estrogens completely or to enhance removal efficiency of the activated sludge process by optimized operation parameters.
Mass flux and output pathways of steroid estrogen in the WWTP

Processes such as volatilization, adsorption, aerobic biodegradation, anaerobic biodegradation, anoxic biodegradation, and photolytic degradation play important roles in the removal of organic contamination in WWTPs. In general, volatilization is determined by Henry's law constant $\left(H_{\mathrm{c}}\right)$ and octanol-water partition coefficients $\left(K_{\text {ow }}\right)$ of organic compounds. Compounds with $H_{\mathrm{c}}>10^{-4}$ and $H_{\mathrm{c}} / K_{\mathrm{ow}}>10^{-9}$ have a high volatilization potential. Conversely, compounds with $H_{\mathrm{c}}>$ $10^{-4}$ and $H_{\mathrm{c}} / K_{\mathrm{ow}}>10^{-9}$ have low volatilization potential (Rogers 1996). The $\log K_{\mathrm{ow}}$ values and $H_{\mathrm{c}}$ of estrogens are $2-4$ and $10^{-12}-10^{-10}$, respectively (Kuster et al. 2004, 2005). This suggests that volatilization output can be ignored for steroid estrogens in WWTPs. Because little sunlight is present during treatment processes, the photolytic degradation of steroid estrogens also can be ignored. Consequently, the output of steroid estrogens in the studied WWTP was simplified to biodegradation, excess sludge, and effluent discharge.

The sample taken on August 28, 2007 was used to assess the fate of steroid estrogens in the WWTP. Based on the sum concentration of steroid estrogens in influent, effluent, and dewatered sludge, the mass flux of steroid estrogens was calculated and is illustrated in Fig. 5. The influent mass of steroid estrogens $(2,785 \mathrm{~g} /$ day $)$ was as $100 \%$ input. The masses of steroid estrogens in excess sludge $(27 \mathrm{~g} /$ day) and in effluent (105 g/day) accounted for $1 \%$ and $3.8 \%$ of the total output at mass balance. The biodegradation portion contributed $95.2 \%$ to the total output. It was obvious that the main removal mechanism of steroid estrogens in the WWTP was biodegradation. Limited data are available for the fate of steroid estrogens in WWTP processes (Ternes et al. 1999a). A previous report has shown that estrogenic activities in wastewater are biodegraded rather than adsorbed on suspended solids during the treatment processes (Körner et al. 2000; Fan et al. 2011). Johnson et al. (2000) found that no indication demonstrated whether biodegradation or sorption is the most important removal mechanism for steroid estrogens. Mastrup et al. (2001) revealed the majority of steroid estrogens remain soluble in effluent, although a considerable amount is adsorbed onto the sludge, and only $<10 \%$ of these compounds are 


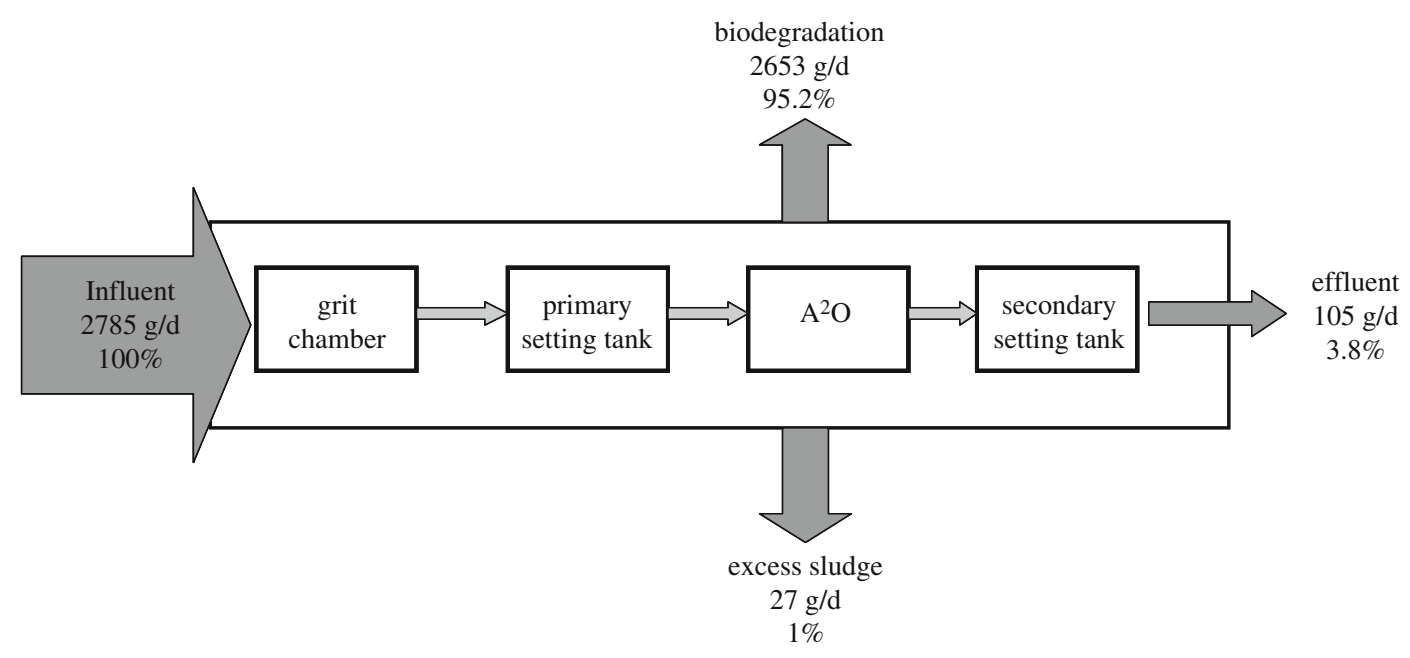

Fig. 5 Mass input and output of steroid estrogens in the WWTP

removed through biodegradation in WWTPs. Documented removal mechanisms of steroid estrogens are with much different in WWTPs. These different removal mechanisms may be due to variable operation processes and parameters.

To understand the fate of each steroid estrogen in the WWTP, the mass balances of E1, E2, E3, and EE2 are illustrated in Fig. 6, which shows that natural estrogens biodegraded by $>95 \%$, while only $26 \%$ of EE2 was biodegraded. The major removal mechanisms in the WWTP were biodegradation for natural estrogens and sorption on sludge for synthetic estrogen EE2. The biodegradation efficiencies of the natural estrogens in this study were correlated with their $\log K_{\mathrm{ow}}$. When the $\log K_{\mathrm{ow}}$ is smaller, the biodegradation removal is higher. According to the $\log K_{\mathrm{ow}}$ of steroid estrogens, E1, E2, and EE2 should appreciably adsorb onto sediment and sludge (Ternes et al. 2002). Only E1 and EE2 appeared in dewatered sludge in the present study, which may be because adsorbed E2 rapidly converted to E1, and then cleaved in the sludge treatment processes. Ternes et al. (1999a) reported that $>95 \%$ of E2 converted to E1 after a period of $1-3 \mathrm{~h}$ under aerobic conditions. However, only $50 \%$ of spiked E2 is converted to E1 after 7 days in anaerobic conditions, after which no further degradation occurs (Lee and Liu 2002). In an activated sludge system, $60 \%$ of EE2 was found bound to the sludge (Layton et al. 2000). Results in this study are consistent with previous studies. The higher EE2 in the dewatered sludge (63\%) may be due to its resistance to bacterial attack and relatively high hydrophobicity.

The occurrence of higher levels of EE2 and E1 in dewatered sludge is of concern. The concentration of EE2 in sludge attained levels up to $4.1 \times 10^{2} \mathrm{ng} / \mathrm{g} \mathrm{dw}$ in the present study. Sludge application on agricultural fields may cause potential contamination of soil and
Fig. 6 Percentage contribution of each steroid estrogen in effluent, in sludge and by biodegraded in the WWTP

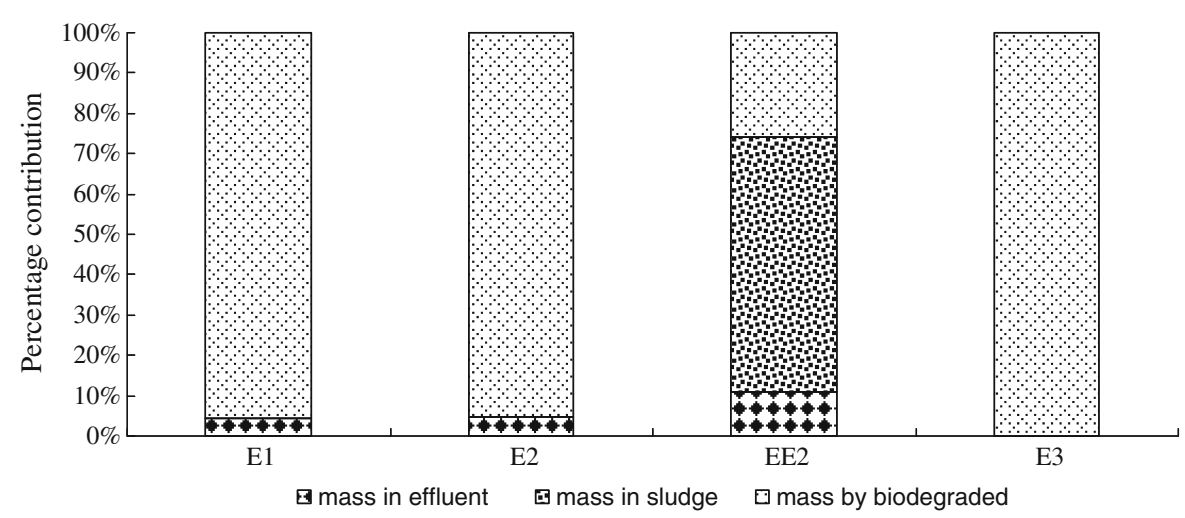


ground water (Ternes et al. 1999b). Although the mass of steroid estrogens in effluent was only $3.8 \%$ of total input, the much higher concentrations of estrogens occurring on the suspended solids in effluent is still a challenge for receiving water. The concentrations of E1, E2, and EE2 on the suspended solids were $42.4 \times$ $10^{2}, 7.7 \times 10^{2}$, and $9.4 \times 10^{2} \mathrm{ng} / \mathrm{g} \mathrm{dw}$. Most previous results have demonstrated that the adsorbed amount of contaminants is determined by particulate size and roughness (Muriel et al. 2006). Therefore, the higher concentration of estrogens in the effluent may be related to the smaller particulate size and surface characteristics of suspended solids. It is difficult to biodegrade steroid estrogens in sediment under anaerobic or anoxic conditions; therefore, the sedimentation of the suspended solid in the receiving water may be an important pollution source for surface and ground water.

\section{Conclusions}

Compared to previous research, the higher influent concentration of estrogens in the present study may be due to higher population density and birthrate in Beijing, and different sampling time points and less individual water consumption. The influent concentration and removal rates appeared to be seasonally characteristic. Variable influent concentrations of estrogens with season may be related to changes in human excretion rates, industrial wastewater discharge, and populations of pregnant women. The higher influent concentration of EE2 in the WWTP may be related to industry discharge or/and different consumption rates of the contraceptive pill.

On the basis of mass balance in water, suspension particles, and sludge, the higher removal of natural estrogens and synthetic estrogen EE2 in the present study depended on biodegradation and sorption. Applied flocculation and sand filtration in the WWTP did not effectively reduce residual estrogens in the secondary sedimentation tank effluent. As the effluent concentrations of steroid estrogens are high enough to induce adverse effects on wild animals, current activated sludge processes should be optimized or other advanced treatment processes considered to eliminate residual estrogen in WWTP effluent completely. Higher levels of estrogen in sludge and suspended solids are of particular concern as they may lead to contamination of soil and surface and ground water. Consequently, the introduction of corresponding laws and practices should be developed to control estrogen pollutants in China.

Acknowledgements We thank Dr. Jun Zhou for providing us with the WWTP information and Dr. Xiaoqing $\mathrm{He}$ for providing us with help during the sampling period. This work was supported by the Chinese Academy of Sciences (KZCX1YW-06) and the National Basic Research Program of China (2007CB407301).

\section{References}

Andersen, H., Siegrist, H., Halling, S. B., \& Ternes, T. A. (2003). Fate of estrogens in a municipal sewage treatment plant. Environmental Sciences and Technology, 37, 40214026.

Atalay, E., Karaali, K., Akar, M., Ari, E. S., Simsek, M., Atalay, S., \& Zorlu, G. (2005). Early impact of hormone replacement therapy on vascular hemodynamics detected via ocular colour. Doppler analysis Maturitas, 50, 282288.

Baronti, C., Curini, R., D’Ascenzo, G., Di Corcia, A., Gentili, A., \& Samperi, R. (2000). Monitoring natural and synthetic estrogens at activated sludge sewage treatment plants and in a receiving river water. Environmental Sciences and Technology, 34, 5059-5066.

Beijing Statistical Yearbook (2006), Beijing Municipal Bureau of Statistics, www.bjstats.gov.cn/tjnj/2006-tjnj/content/ mV98_08-10.htm.

Belfroid, A. C., Van der Horst, A., Vethaak, A. D., Schäfer, A. J., Rijs, G. B. J., Wegener, J., \& Cofino, W. P. (1999). Analysis and occurrence of estrogenic hormones and their glucuronides in surface water and waste water in The Netherlands. The Science of the Total Environment, 225, 101-108.

Birkett, J. W., \& Lester, J. N. (2003). Endocrine Disrupters in Wastewater and Sludge Treatment Processes. Boca Raton London New York Washington, D.C: ACRC Press Company.

Blok, J., Wösten, M. A. D. (2000). Origin and fate of natural estrogens in the environment (in Dutch) RIWA. Amsterdam, Haskoning.

Braga, O., Smythe, G., Schafer, A. I., \& Feitz, R. J. (2005). Fate of steroid estrogens in Australian inland and coastal wastewater treatment plants. Environmental Sciences and Technology, 39, 3351-3358.

Carballa, M., Fink, G., Omi, 1. F., Lema, J. M., \& Ternes, T. (2008). Determination of the solid-water distribution coefficient $(\mathrm{Kd})$ for pharmaceuticals, estrogens and musk fragrances in digested sludge. Water Research, 42, 287295.

Cargouët, M., Perdiz, D., Mouatassim, S. A., Tamisier, K. S., \& Levi, Y. (2004). Assessment of river contamination by estrogenic compounds in Paris area (France). The Science of the Total Environment, 324, 55-66. 
Chang, H., Wan, Y., Wu, S., Fan, Z., \& Hu, J. (2011). Occurrence of androgens and progestogens in wastewater treatment plants and receriving river waters: Comparison to estrogens. Water Research, 45, 732-740.

Chen, C., Wen, T., Wang, G., Cheng, H., Lin, Y., \& Lien, G. W. (2007). Determining estrogenic steroids in Taipei waters and removal in drinking water treatment using high-flow solid-phase extraction and liquid chromatography/tandem mass spectrometry. The Science of the Total Environment, 378, 352-365.

Christensen, F. M. (1998). Pharmaceuticals in the environment; a human risk? Regulatory Toxicology Pharmmacology, 28 (3), 212-221.

Clara, M., Strenn, B., Saracevic, E., \& Kreuzinger, N. (2004). Adsorption of bisphenol-A, $17 \beta$-estradiole and $17 \alpha$ ethinylestradiole to sewage sludge. Chemosphere, 56, 843-851.

Cui, C., Ji, S., \& Ren, H. (2006). Determination of steroid estrogens in wastewater treatment plant of a controceptives producing factory. Environmental Monitoring and Assessment, 121, 409-419.

D’Ascenzo, G., Di Corcia, A., Gentili, A., Mancini, R., Mastropasqua, R., Nazzari, M., \& Samperi, R. (2003). Fate of natural estrogen conjugates in municipal sewage transport and treatment facilities. The Science of the Total Environment, 302, 199-209.

David, R. H., John, T. N., Thomas, J. G., \& Nancy, G. L. (2002). Estrogen receptor agonist fate during wastewater and biosolids treatment processes: A mass balance analysis. Environmental Sciences and Technology, 36, 4533-4539.

Desbrow, C., Routledge, E. J., Brighty, G. C., Sumpter, J. P., \& Waldock, M. (1998). Identification of estrogenic chemicals in STW effluent. 1. Chemical fractionation and in vitro biological screening. Environmental Sciences and Technology, 32, 1549-1558.

Fan, Z., Wu, S., Chang, H., \& Hu, J. (2011). Behavior of glucocorticoids, androgens and progestogens in a municipal sewage treatment plant: Comparison to estrogens. Environmental Sciences and Technology, 45, 2725-2733.

Fawell, J. K., Sheahan, D., James, H. A., Hurst, M., \& Scott, S. (2001). Oestrogens and oestrogenic activity in raw and treated water in Seven Trent Water. Water Research, 35(5), 1240-1244.

Jin, S., Yang, F., Liao, T., Hui, Y., \& Xu, Y. (2008). Seasonal variation of estrogenic compounds and their estrogenicities in influent and effluent from a municipal sewage treatment plant in China. Environmental Toxicology and Chemistry, 27(1), 146-153.

Jobling, S., Nolan, M., Tyler, C. R., Brighty, G., \& Sumpter, J. P. (1998). Widespread sexual disruption in wild fish. Environmental Sciences and Technology, 32, 2498-2506.

Johnson, A. C., \& Sumpter, J. P. (2001). Removal of endocrine disrupting chemicals in activated sludge treatment works. Environmental Sciences and Technology, 35(24), 46974703.

Johnson, A. C., \& Williams, R. J. (2004). A model to estimate influent and effluent concentrations of estradiol, estrone, and ethinylestradiol at sewage treatment works. Environmental Sciences and Technology, 38(13), 3649-3658.

Johnson, A. C., Belfroid, A., \& Di Corcia, A. (2000). Estimating steroid oestrogen inputs into activated sludge treatment works and observations on their removal from the effluent. The Science of the Total Environment, 256(23), 163-173.

Katzung, B. G. (1995). Basic \& clinical pharmacology. Norwalk, Connecticut: Appleton \& Lange.

Kirk, L. A., Tyler, C. R., Lye, C. M., \& Sumpter, J. P. (2002). Changes in estrogenic and androgenic activities at different stages of treatment in wastewater treatment works. Environmental Toxicology and Chemistry, 21(5), 972-979.

Kolpin, D. W., Furlong, E. T., Meyer, M. T., Thurman, E. M., Zaugg, S. D., Barber, L. B., \& Buxton, H. T. (2002). Pharmaceuticals, hormones, and other organic wastewater contaminants in U.S. streams, 1999-2000: A national reconnaissance. Environmental Sciences and Technology, 36, 1202-1211.

Körner, W., Bolz, U., Sussmuth, W., Hiller, G., Schuller, W., Hanf, V., \& Hagenmaier, H. (2000). Input/output balance of estrogenic active compounds in a major municipal sewage plant in Germany. Chemosphere, 40, 1131-1142.

Kuster, M., Maria, J. L. A., \& Barcelo, D. (2004). Analysis and distribution of estrogens and progestogens in sewage sludge, soils and sediments. TrAC Trends in Analytical Chemistry, 23(10-11), 790-798.

Kuster, M., Alda, M. J. L., \& Barceló, D. (2005). Estrogens and progestogens in wastewater, sludge, sediments, and soil (pp. 1-24). Verlag Berlin Heidelberg: Springer.

Lai, K. M., Johnson, K. L., Scrimshaw, M. D., \& Lester, J. N. (2000). Binding of water borne steroid estrogens to solid phases in river and estuarine systems. Environmental Sciences and Technology, 34, 3890-3894.

Larsson, D. G. J., Adolfsson-Erici, M., Parkkonen, J., Pettersson, M., Berg, A. H., Olsson, P. E., \& Forlin, L. (1999). Ethinyloestradiol-An undesired fish contraceptive? Aquatic Toxicology, 45, 91-97.

Layton, A. C., Gregory, B. W., Seward, J. R., Schultz, T. W., \& Sayler, G. S. (2000). Mineralization of steroidal hormones by biosolids in wastewater treatment systems in Tennessee U.S.A. Environmental Sciences and Technology, 34(18), 3925-3931.

Lee, H. B., \& Liu, D. (2002). Degradation of $17 \beta$-eatradiol and its metabolites by sewage bacteria. Water, Air, \& Soil Pollution, 134, 353-368.

Lei, B., Huang, S., Zhou, Y., Wang, D., \& Wang, Z. (2009). Levels of six estrogens in water and sediment from three rivers in Tianjin area, China. Chemosphere, 76, 36-42.

Ma, T., Wan, X., Huang, Q., Wang, Z., \& Liu, J. (2005). Biomarker responses and reproductive toxicity of the effluent from a Chinese large sewage treatment plant in Japanese medaka (Oryzias latipes). Chemosphere, 59, 281-288.

Ma, M., Rao, K., \& Wang, Z. (2007). Occurrence of estrogenic effects in sewage and industrial wastewaters in Beijing, China. Environmental Pollution, 147, 331-336.

Maggs, J. L., Grimmer, S. F. M., L'e-Orme, M., Breckenridge, A. M., Park, B. K., \& Gilmore, I. T. (1983). The biliary and urinary metabolites of $\left[{ }^{3} \mathrm{H}\right] 17 \alpha$-ethynylestradiol in women. Xenobiotica, 13(7), 421-431.

Martinović, D., Denny, J. S., Schmieder, P. K., Ankley, G. T., \& Sorensen, P. W. (2008). Temporal variation inthe estrogenicity of a sewage treatment plant effluent and its biological significance. Environmental Sciences and Technology, 42, 3421-3427. 
Mastrup, M., Jensen, R. L., Schfäer, A. I., \& Khan, S. (2001). Fate modeling-An important tool for water recycling. In A. I. Schfäer, P. Sherman, \& T. D. Waite (Eds.), Recent advances in water recycling technologies (pp. 103-112). Brisbane: Australia.

Matsui, S., Takigami, H., Matsuda, T., Taniguchi, N., Adachi, J., Kawami, H., \& Shimizu, Y. (2000). Estrogen and estrogen mimics contamination in water and the role of sewage treatment. Water Science and Technology, 42, 173-179.

Means, J. C., Wood, S. G., Hasset, J. J., \& Banwart, W. L. (1982). Sorption of amino- and carboxy-substituted polynuclear aromatic hydrocarbons by sediments and soils. Environmental Sciences and Technology, 16(2), 93-98.

Muriel, A., Youssef, F. M., Rajeshwar, D. T., Craig, D. A., \& Rao, Y. S. (2006). Endocrine disrupting compounds removal from wastewater, a new challenge. Process Biochemistry, 41, 525-539.

Nakada, N., Shinohara, H., Murata, A., Kiri, K., Managaki, S., Sato, N., \& Takada, H. (2007). Removal of selected pharmaceuticals and personal care products (PPCPs) and endocrine-disrupting chemicals (EDCs) during sand filtration and ozonation at a municipal sewage treatment plant. Water Research, 41, 4373-4382.

Ong, P. E. A., Chang, S., Waite, T. D., Schäfer, A. I. Fane AG. Removal of trace contamination using coagulation, PAC and microfiltration hybrid processes. In: Recent advances in water recycling technologies. 26 November 2001 Workshop, Brisbane.

Peter, G. F. (1990). Metabolism of 17 [alpha]-ethynylestradiol in humans. Life Sciences, 47, 1981-1988.

Ranney, R. E. (1977). Comparative metabolism of $17 \alpha$-ethynyl steroid used in oral contraceptive. Journal of Toxicology and Environmental Health, 3, 139-166.

Rodgers-Gray, T. P., Jobling, S., Morris, S., Kelly, C., Kirby, S., Janbakhsh, A., Harries, J. E., Waldock, M. J., Sumpter, J. P., \& Tyler, C. R. (2000). Long-term temporal changes in the estrogenic composition of treated sewage effluent and its biological effects on fish. Environmental Sciences and Technology, 34, 1521-1528.

Rogers, H. R. (1996). Sources, behaviour and fate of organic contaminants during sewage treatment and sewage sludges. The Science of the Total Environment, 185, 3-26.

Routledge, E. J., Sheahan, D., Desbrow, C., Brighty, G. C., Waldock, M., \& Sumpter, J. P. (1998). Identification of estrogenic chemicals in STW effluent. 2. In vivo responses in trout and roach. Environmental Sciences and Technology, 32, 1559-1565.

Servos, M. R., Bennie, D. T., Burnison, B. K., Jurkovic, A., McInnis, R., Neheli, T., Schnell, A., Seto, P., Smyth, S. A., \& Ternes, T. A. (2005). Distribution of estrogens, 17 [beta]-estradiol and estrone, in Canadian municipal wastewater treatment plants. The Science of the Total Environment, 336, 155-170.

Shore, L. S., Gurevitz, M., \& Shemesh, M. (1993). Estrogen as an environmental pollutant. Bulletin of Environmental Contamination and Toxicology, 51, 361-366.
Sun, Q., Deng, S., Huang, J., Shen, G., \& Yu, G. (2007). Contributors to estrogenic activity in wastewater from a large wastewater treatment plant in Beijing, China. Environmental Toxicology and Pharmacology, 25, 20-26.

Svenson, A., Allard, A., \& Ek, M. (2003). Removal of estrogenicity in Swedish municipal sewage treatment plants. Water Research, 37(18), 4433-4443.

Tabak, H. H., Boomhuff, R. N., \& Bunch, R. L. (1981). Steroid hormones as water pollutants II. Studies on the persistence and stability of natural urinary and synthetic ovulationinhibiting hormones in untreated and treated wastewaters. Dev. Ind. Microbiol., 22, 497-519.

Ternes, T. A. (1998). Occurrence of drugs in German sewage treatment plants and rivers. Water Research, 32(11), 32453260 .

Ternes, T. A., Kreckel, P., \& Mueller, J. (1999). Behavious and occurrence of estrogens in municipal sewage treatment plants-II. Aerobic batch experiments with activated sludge. The Science of the Total Environment, 225, 91-99.

Ternes, T. A., Stumpf, M., Mueller, J., Haberer, K., Wilken, R. D., \& Servos, M. (1999). Behavious and occurrence of estrogens in municipal sewage treatment plants-I. Investigation in Germany, Canada and Brazil. The Science of the Total Environment, 225, 81-90.

Ternes, T. A., Andersen, H., Gilberg, D., \& Bonerz, M. (2002). Determination of estrogens in sludge and sediments by liquid extraction and GC/MS/MS. Analytical Chemistry, 74, 3498-3504.

Tyler, C. R., Jobling, S. R., \& Sumpter, J. P. (1998). Endocrine disruption in wildlife: a critical review of the evidence. Critical Reviews in Toxicology, 28, 319-361.

US Environmental Protection Agency. (1997). Special report on environmental endocrine disruption: An effects assessment and analysis, Washington, DC, USA, $111 \mathrm{p}$.

Vethaak, A. D., Lahr, J., Schrap, S. M., Belfroid, A. C., Rijs, G. B. J., Gerritsen, A., de Boer, J., Bulder, A. S., Grinwis, G. C. M., Kuiper, R. V., Legler, J., Murk, T. A. J., Peijnenburg, W., Verhaar, H. J. M., \& de Voogt, P. (2005). An integrated assessment of estrogenic contamination and biological effects in the aquatic environment of The Netherlands. Chemosphere, 59, 511-524.

Zha, J., Sun, L., Zhou, Y., Ma, M., \& Wang, Z. (2008). Assessment of 17a-ethinylestradiol effects and underlying mechanisms in a continuous, multigeneration exposure of the Chinese rare minnow (Gobiocypris, rarus). Toxicology and Applied Pharmacology, 226, 298-308.

Zhou, Y., Zhou, J., Xu, Y., Zha, J., Ma, M., \& Wang, Z. (2009). An alternative method for the determination of estrogens in surface water and wastewater treatment plant effluent using pre-column trimethylsilyl derivatization and gas chromatography/mass spectrometry. Environmental Monitoring and Assessment, 158, 35-49.

Zhou, Y., Zha, J., Xu, Y., Lei B., Wang Z. (2011). Occurrences of six steroid estrogens from different effluents in Beijing, China. Environmental Monitoring and Assessment, in press. 